\title{
A VIGILÂNCIA PRIVADA - AUXILIAR DO SISTEMA DE PROTEÇÃO E DEFESA SOCIAL
}

\author{
ALMIR CHAGAS VILEL,A *
}

O tema comporta três desdobramentos:

O primeiro, ligado ao direito de auto-proteção física, pessoal, do cidadão;

O segundo, ligado ao direito de proteção de pessoas jurídicas;

$\mathrm{O}$ terceiro, ligado ao aspecto de uma atividade que complementa, auxiliarmente as missões oficiais do Estado de exercer polícia e segurança em geral, braço extensor da Justiça Pública.

Principiaríamos com aigumas indagações à guisa de reflexão no curso da exposição:

1 - A precipitação de fatores indesejados como explosão demográfica, inchamento urbano, desiquilíbrios econômico-sociais, instiabilidade política não estarão expandindo e degenerando o panorama delinquencial?

2 - A ampliação da ação do Estado em áreas que não lhe seriam fundamentais, não estaria desiquilibrando a atualização do sistema de defesa e proteção-social composto da Polícia, Ministério Público, Justiça Criminal e sub-Sistema Prisional?

3 - As deficiências assistenciais nas áreas de saúde, educação e alimentação não estariam gerando um quadro patológico, síndrome de uma violência a luz de como são perpetrados delitos e o volume que ocorrem?

4 - O engorgitamento do sistema estatal de proteção e defesa cujas conseqüências desaguam nos perigosos níveis de burla às sanções não contribuem para a desestabilização das condições pré-existenciais de ordem e paz pública?

5 - Os recursos e dispositivos oficiais bastar-se-iam para, senão desacelerar, pelo menos minimizar os efeitos ou consequiências em termos de vidas humanas e bens patrimonais?

6 - Finalmente, está o Estado capacitado ou habilitado a assegurar efetiva defesa e proteção dos cidadãos e às comunidades?

O crescente aumento dos delitos atentatórios ao patrimônio, arrombamentos de residências, assaltos a mão armada, furto nas

- Professor Assistente do Departamento de Direito Público do Setor de Ciências Jurídicas da UFPr. 
vias públicas marcados com o sinete da requintada violência, quando perpetrados indistintamente e o preocupante surto delinqüencial com entrechoques de interesses de ordem econômica e social, proliferação de menores adentrando a marginalidade e aparecimento de formas de crime organizado ou grupal não obstados pelo sistema de proteção criminal, impele o cidadão a se precaver através do uso indiscriminado de armas.

A proteção não mais se circunscreve a incolumidade pessoal para envolver, também, um complexo técnico e não raro sofisticado que evita danos materiais, reduz as perdas, diminui prejuízos além de constituir boa garantia contra vandalismos e incêndios.

Há um direito formal e informal extraível dos princípios constitucionais que assegura ao cidadão o poder de se resguardar contra atos que ponham em risco sua vida, de seus familiares e seus bens.

Dos direitos fundamentais do homem, o da vida e da liberdade embasam toda uma concepção de SER e de SOCIEDADE de vida comunitária cujas limitações no interesse maior da coletividade jamais poderiam se contrapor ou contrariar a garantia de uma vida tranquila duradoura e de liberdade para a pacífica escolha dos amplos horizontes que cada um descortina.

As ameaças que se produzem e que possam por em risco esses direitos, imprevisíveis aquelas como sóe ocorrer com o próprio destino e impossíveis de serem obstadas ou contidas pelo Poder Público, justificam, a luz mesmo das garantias individuais es. tabelecidas na lei máxima, o direito de autoproteção, de autodefesa, o direito de cada um precaver-se contra o ímpeto de uma potencial e agressiva ameaça desde que, evidentemente, a seqüência de atos tradutores do estado de ameaça tipifiquem um comportamento criminoso.

Se, em tese e genericamente ao Poder Público cabe a missão de garantir os direitos e assegurar a inviolabilidade dos bens materiais e da vida humana, não pode ele, no mundo contemporâneo estar onipresente, nem seria crível conceber-se representado e protegendo, individualmente cada cidadão e provendo segurança ao patrimônio dos componentes da sociedade que optou por esta ou aquela forma de governo.

Tentando evitar o comprometimento da normalidade jurídica, o Poder Público, pelos organismos de segurança agem ou deveriam atuar preventivamente que, no campo do delito ou contravenção é meramente simbólica, verificável pelo aclive da linha criminal, pela constância das normas violacias, pela audácia como são cometidos e pelo estado de angústia e preocupação popular que revelam uma significativa ausência da atividade preventiva estatal. 
O Governo, nos momentos em que o crime evolui e se avoluma toma decisões ratificatórias do direito de autoproteção; assim é que usando dos poderes especiais e transitórios que o extinto processo revolucionário se investiu, OBRIGOU Bancos e similares a se protegerem criando um sistema de proteção bancária; deixou de ser uma convenièricia ou faculdade de cada um para se tornar uma necessidade publicamente reconhecida mas IMPOSTA pelo Poder Público: (Decreto Lei 1034 de 1969); nesta mesma linha de ação as denominadas ATIVIDADE ESSENCIAIS AO ESTADO (luz, água, telefone, combustível e transporte - Decreto Lei 898 de 1969), no interesse maior da coletividade foram OBRIGADAS, a produzirem sistemas de proteção próprios ou contratados de empresas especializadas, também a corstituição reconheceu, oportunamente às Municipalidades instituirem Guardas Municipais que concorrem, no policiamento ostensivo à proteção dos bens públicos municipais.

Vozes inadvertidas já propugnaram a proibição da vigilância particular em franca negaçăo ao direito de autoproteção, em oposição antagônica a ação governamental.

Poderia ser perguntado: quem poderia proibir ou impedir que um cidadão disponha de un ou mais elementos humanos ou instrumentos materiais para proteger sua família, para vigiar sua propriedade nos períodos diurno e noturno, fiscalizável, simplesmente a utilização eventual de arma que dependerá de prévia autorização do Poder Público?

Qualquer manifestação de autoridade pública nesse sentido, desamparada legalmente, consistirá, inequivocamente em ato arbitrário reparado pela via do mandado de segurança ou de 'habeas corpus' e sancionada pelo abuso do poder verificado, segundo dispõe a Lei 4.898 que define os crimes de abuso de poder.

Não é da formação nacional conferir absolutos poderes a governo ou pessoas, da mesma forma que inadmissível a liberdade absoluta, sob pena da nação ser lançada ora ao despotismo fascista e ora ao estado anárquico. O sistema democrático de governo se afirma e se consolida ao evitar uma ou outra.

Quando se anuncia POLICIAMENTO OSTENSIVO, se vincula a ação governamental de POLICIA e SEGURANÇA, dois termos de cunho e acepção nitidamente oficial, definidores de atividades amplas ou restritas mas privativas do Poder Público.

Sem pretender criar eufemismos há que, contudo, em sentido policiológico, distinguir as atividades imanentes do Poder Público - POLfCIA e SEGURANÇA das ações do PARTICULAR PROTEÇÃO e VIGILÂNCIA. São distintas e não se confundem muito embora possam superficialmente julgar que todas tem um único sentido ou tenham o mesmo conteúdo ou, até, que não 
passam de uma questão de sinonímia. Exercitando POLfCIA e SEGURANÇA estará o Estado desempenhando completamente uma atividade interligada de proteção ou vigilância, com as limitações do direito individual. Em contrapartida a proteção e a vigilância se eregem como conseqüência do capítulo dos direitos e garantias individuais, com um sentido restritivo ao espaço físico onde é exercida, e eventual fiscalização quando a lei a enunciar, sem tolhê-la.

Embora, nos Estados Unidos, a própria Constituição Federal assegure ao cidadão o direito inalienável: "right of the people to keep and bear arms", direito do povo de possuir e portar armas, o Governo Federal empreende extensa campanha visando a não programação do seu uso e o decréscimo das enormes quantidades existentes que ascendem de 30 a 50 milhões somente em armas de defesa (hand guns); o Diretor do FBI, em mensagem transmitida às demais organizações policiais do hemisfério norte, externou sua imensa preocupação com o assunto acrescentando, alusivamente à disposição constitucional, que o "exercício ilimitado de qualquer direito não deverá ser tolerado quando o público está em perigo"; a vida humana - conclui - inquestionavelmente deve ser um valor respeitado na civilização.

Não é, claramente, o remédio compatível para a cura do mal epidêmico da violência e do medo que contamina pessoas e se propaga contagiosamente a nações inteiras.

PETER RANDOGSTEN, psicólogo e catedrático de Universidade na Califórnia testemunhou que "o crime e a conseqüente questão de defesa dos cidadãos, é o maior problema dos Estados Unidos. O medo acabou penetrando em todas as camadas da sociedade norte-americana".

Hoịe o crime de rua transformou-se em verdadeira comoção comunitária. Tal a exacerbação e ímpeto como vem sendo amplamente perpetrado; exemplificadamente, em Nova York e Washington, já com estado de emergência de segurança pública reconhecido.

O caminho, obviamente, que conduza a paz comunitária não será por certo, do medievalismo de encastelar-se, apetrechar-se e pretender avocar, à guisa de direito de defesa, a prerrogativa de sancionar o justicialismo pessoal, implacável $€$ insensato. A lei de Linch deixa refletir a inocuidade da função estatal.

Todavia, se destacarmos que as investidas contra os bens patrimoniais e a própria vida, já a qualquer hora, e em proporções significativamente alarmantes, que se somam as maneiras cruéis e violentas como são perpetradas - não sendo uma peculiaridade patrícia, já causaram reações de indignação e protesto público do próprio aparelho policial governamental como noticiam, ulti- 
mamente, as informações publicadas relatando eventos ocorridos em alguns países, originados pela total insegurança física e jurídica do exercício de manutenção da ordem, concluiremos então, o dever fundamental, senão o direito consagrado do cidadão de buscar DETERMINADOS e RAZOÁVEIS meios para sua proteção, assecuratórios de uma vida tranquila na sociedade e comunidade que escolheu.

PATRICK MENEY, da Agência France Press, em cobertura sobre a Polícia Italiana observa que em suas assembléias gerais os italianos confessam que "não estão em condições de proteger o cidadão", impondo-se, daí, o estudo e reexame do multiforme poder repressivo penal no embate com as novas contingências do relacionamento social.

Se o Poder Público revela-se incapacitado para prover os requisitos de segurança coletiva, ipso facto, proteção do cidadão que integra o núcleo comunitário, não há como admitir-se exclusividade ou monopólio de exercitamento do "munus" correspondente; vamos mais longe ao afirmarmos que, com a redistribuição do bolo da receita imposta pela nova Constituição haveria que ter uma mais justa repartição do Poder de Polícia entre a União, o Estado e o Município, sobretudo com uma maior e decisiva participação deste último, aliviando a preponderância que sobrecarrega o Estado membro.

Entre a ampliação desmedida da força policial e do aparato de segurança, sintomático prenúncio do Estado Policial, eregindo-se em poderoso organismo na órbita governamental, impositor de demandas, exigente de privilégios e transformando-se em poderoso grupo de pressões, desvirtuando-se de seus objetivos e finalidades, propenso a escapar a eficiência dos dispositivos controladores e mecanismos de fiscalização no sistema de pesos e contra-pesos do regime democrático, deferiu-se, ao particular, o direito e a prerrogativa indeclinável de se auto-proteger, preenchendo o vazio da atividade estatal, cobrindo a lacuna que a segurança global da coletividade atribui fundamentalmente aos órgãos de polícia; complementa o cidadão a sua segurança, em um círculo mais próximo e limitado, assegurando-se que a sensação do bem-estar geral se torne real e tanto quanto possível efetiva, ampla e plena.

A necessidade que tem o cidadão de se realizar e contribuir para o desenvolvimento acelerado e progresso constante da nação condiciona-se a sua trajetória ascendente, construtiva e tranquila, só alcançável com o sentimento firme de confiança na sua integridade, na de seus bens.

Este autêntico "munus" remonta suas origens ao próprio "direito natural", logo mais cristalizado na vontade expressa dos so- 
beranos e, posteriormente, nos princípios geradores das constituições, surgindo como regra primária da coexistência em sociedade e irmanador da vida em comunidade.

Verificou-se que esta autoproteção facultativa mas inerente aos cidadãos, quando não exercitada, faz coagir o governo a impô-la, a obrigá-la como sucede com as instalações definidas como "essenciais ao Estado" e aos "estabelecimentos de crédito e financiamento" (Decretos Leis 898 e 1.034).

Nos dias correntes, a ativação das medidas de vigilância e proteção se ampliam da pessoa física à pessoa jurídica: do cidadão e sua família à sociedade a qualquer título e a seus elementos. constitutivos.

A necessidade do homem de autoproteção e de sua propriedade é elemento essencialmente básico para a sua existência. Este condicionante da liberdade incrusta-se na própria sobrevivência da democracia e se insere como postulado constitucional agasalhado pela maioria das nações que se inspiram na Independência Americana e na Revolução Francesa. HAROLD J. LASKI a propósito em 1930 escrevia que a "insegurança é a antitese essencial da liberdade".

A necessidade de proteção ou segurança individual e de seus bens patrimoniais, o direito de preservar-se quanto à agressões que vulnerem sua incolumidade física ou de atentados que exponham seus bens e recursos a danos que alterem sua estabilização na sociedade respalda-se em consensos universais cristalizados na "Declaração Universal de Direitos do Homem da Organização das Nações Unidas (1948: "toda pessoa tem direito a liberdade e a segurança da sua pessoa (Art. 3.0) e "todos tem o direito de ser protegidos (Art. 7.0) ainda na "Convenção Européia da Salvaguarda dos Direitos do Homem e das Liberdades Fundamentais (1950) quando prescreve que "toda pessoa tem o direito a liberdade e a segurança". Complementam os fundamentos consagrados no mundo contemporâneo e aceitos înternacionalmente, o "Pacto Internacional dos Direitos Civis e Políticos" (Assembléia Geral da ONU - 1966) quando afirma "o direito à segurança pessoal ao lado do direito à vida e a liberdade e a "Convenção Americana sobre os Direitos Humanos" (São José da Costa Rica - 1966) ao enfatizar "o direito à segurança pessoal".

Fiel a esta conduta, a nova Constituição brasileira, agora no Artigo $5 .^{\circ}$ e não mais no Artigo 153 da carta de 1969 assegura, sob o título - Dos direitos individuais e coletivos - e garante "a inviolabilidade do direito à. vida, à liberdade, à segurança e a propriedade".

A garantia de proteção assegurada pelo Estado, longe de ser absoluta e plena, se não abstrata ou puramente normativa, apre- 
senta, mais a certeza de prover segurança ampla, coletiva, geral, no sentido do equilíbrio social e manutenção da disciplina comunitária do que, propriamente, o que seria inviável, a proteção individual exclusiva a todos os integrantes do corpo social.

Vale-se o Estado, do instrumento policial a "criar segundo RUI CIRNE LIMA condições gerais indispensáveis para que os indivíduos em ordem e harmonia logrem conduzir, através do convívio cotidiano e desenvolvimento de suas relações sociais...: muito embora promova o "bem individual e o bem social e, ainda, a própria utilidade pública, porque, sob esse aspecto a proteção ao indivíduo e ao segregado é essencial à existência da sociedade, bem em si mesma" - esta proteção manifesta-se quando ferido o indivíduo ou lesados seus bens ou na iminência de o ser ou quando uma potencialidade ou expectativa possa afetar ou por em risco a sua segurança pessoal ou a sua propriedade.

A segurança do cidadão é exercitada não em função propriamente do indivíduo, como ente isolado carecedor de proteção mas como parcela do aglomerado social, visto primariamente como um todo e em segundo plano individualizado na sociedade; poderíamos dizer que a proteção se ativa interdependente interligando-se de indivíduo a indivíduo na rua, nos bairros, nas áreas rurais, urbanas e regionais a atingir os limites territoriais, com extensão em casos pré-determinados à outras unidades soberanas.

Muito embora esta visão não corresponda aos caminhos perlustrados pelos artífices do pensamento humano e a interpretação e anseios de sociólogos e criminalistas, é todavia, por uma série de disfunções das atividades do Governo, uma realidade que vem demandando estudos mais profundamente elaborados do processo evolutivo da sociedade deste final de século.

A Polícia - ensina o professor argentino RAFAEL BIELSA "tem o poder jurídico de promover o bem jurídico de promover 0 bem estar geral".

As responsabilidades tradicionalmente conferidas a organização de manutenção ảa ordem, entre outras, fundamentadas no princípio da democracia - de proteger os direitos e liberdades de um indivíduo - "protect the rights and liberties of an individual" sofrem, neste específico particułar, visíveis sinais de um processo de erosão.

Analogamente, definições genéricas que não delimitam os marcos da segurança individual da coletiva, os graus de precedência e os níveis de atingimento de ambas, assumem o risco de se extraviarem na incógnita multiforme de interpretações e conceitos irreais.

A noção de Polícia tem se enriquecido com o suceder de mudanças evolutivas. Ainda RAFAEL BIELSA, em seu "Derecho Ad- 
ministrativo y Ciência de la Administracion" - tomo III 83/84, ensina que - "No conceito hoje dominante de polícia compreende-se a faculdade ou poder jurídico, por parte da administração pública, de estabelcer limitações e exercer, coativamente, sua atividade com o fim de regular o USO DA LIBERDADE PESSOAL e PROMOVER O BEM ESTAR GERAL". Bem estar geral - do corpo social, da comunidade globalizada primariamente e do interrelacionamento dos indivíduos, secundariamente, objetivando, ainda nesse sentido, a sociedade como ente coletivo.

Mas, os perigos do crime - lesionador da proteção individual - assumem características extraordinariamente inquietantes. MANUEL LOPES REY em trabalho dado a público sobre o CRIME alicerçando-se em estudos e pesquisas procedidas em vários paí. ses ("CRIME" - pág. 226) escreve que a "insegurança tanto individual como coletiva está se tornando um dos aspectos mais característicos do nosso tempo" destacando, inicialmente, que "tanto nos países desenvolvidos como nos países em desenvolvimento o crime está em expansão" (pág. 1). Impondo-se a necessidade de "garantir certeza e segurança ao indivíduo" (pág. 5).

HOWARD JONES, criminologista inglês inicia seu excelente livro "O crime numa sociedade em evolução", afirmando haver "atualmente mais roukos que nunca, mais destruição tanto da propriedade privada como pública e, mais importante, talvez, um recrutamento grande de crimes de violência contra as pessoas. Os crimes de violência são ainda relativamente poucos no total; a TENDÊNCIA É QUE É INQUIETANTE”.

MANUEL LOPEZ REY, op. cit. pág. 37, é sintomaticamente incisivo ao acrescentar que "os danos materiais intencionais, o número de casos conhecidos mas não relatados é certamente muito mais alto do que o que aparece nas estatísticas policiais. O vandalismo da propriedade privađa, dos transportes e instalações das estradas de ferro, das cabines telefônicas, das lojas, etc., já se tornou um acontecimento banal".

Por outro lado, miais clamorosos são os apelos da imprensa escrita e falada, notadamente aquela dedicada aos fatos policiais quanto à desproteção do indivíduo e a insegurança da população.

Vivemos, daí, a plenitude da "ERA DA SEGURANÇA"; esta última metade do século assoma, nos registros da História como a época da "REVOLUÇÃO DA SEGURANÇA".

Revolução Industrial, Revolução Social e Revolução da Segurança são fenômenos que eclodem passando a caracterizar um tempo de civilização, uma fase limite da caminhada humana, necessidades imperativas ou correção de distorções que vão se ajustando, se acondicionando no amoldamento às aspirações do indivíduo, da coletividade, dos povos. 
A voracidade absorvente de uma sociedade de consumo que de esguela vê o espectro da fermentação demográfica e das colméias humanas massacrantes, lançando-se ao abandono de convicções centenares ou criando as próprias, a abrogação dos valores éticos e culturais, a rejeição do sentimento religioso, liberando os freios disciplinadores da vida em sociedade, faz ressurgir o ser que se aproxima, em ligação no tempo e no espaço, não aquele presumivelmente evoluído de outra constelação ou galaxia mas ao primitivo troglodita com todas as potencialidades negativas já agora, com a sabedoria maligna e terrena de vários séculos.

Individualmente ou em grupos, libertaram os instintos e as tendências que põem em pânico a vida diária; sob inquietantes formas e sob vestes indisfarçáveis do mal comum ou do fanatismo ideológico, intranquilizam permanentemente a todos os extratos da sociedade contemporânea, periclitam a segurança individual e se tornam perigosas sombras que assediam, a todo instante, a propriedade e os bens, a vida e o progresso.

RONALDO S. WOODRUFF, em recente livro lançado nos Estados Unidos, sob o título "Security Techniques" anota, inicialmente, que a "history of security", a história da segurança é vista como uma combinação sequencial de eventos iniciados milhares de anos antes de Cristo e como uma expectativa de continuidade em um tempo ou época ainda por vir.

Não há notícias de que a plena segurarça, a saber, a sensação de tranquilidade resultante da convicção de que não há perigo a temer conforme define AURÉLIO DE LYRA TAVARES, em a "Segurança Nacional", pág. 19 - caracterize a normalidade na vida de uma pessoa em qualquer sociedade.

Dos tempos primitivos, atravessando a Idade Média até a época contemporânea, o ser humano, isolado ou grupalmente, não deixou de sofrer perigos constantes, previsíveis ou imprevisíveis, de crimes e atentados que impedem a realização do "bem estar geral" - do corpo social, da comunidade globalizada primariamente e que contrariam a meta de atingir o "bem comum", em o qual, na expressão de Jacques Maritain em "O Homem e o Estado" pág. 21, se integram incorporados, o senso da lei, da liberdade, a atividade material e a riqueza espiritual".

A sociedade ideal, utópica, pregada desde há milênios, ainda hoje transposta ao mundo da fantasia e ficção, não revelou os mais simples traços de seus contornos; muito pelo contrário, o ceticismo passa a ser aceito, após um período de experimentação de ideologias que provaram a incapacidade do "Estado Ideal" ser alcançado, da "sociedade perfeita", a que alude JACQUES MARITAIN interpretando São Tomás de Aquino e o próprio ARISTÓTELES ser atingida quando defende a necessidade de uma "sociedade universal". 
A instabilidade permanente, hoje ainda mais acelerada e agravada no seio social, predispõe alguns teóricos como EDWARD BAINFIELD da Universidade da Liberdade através da criação de condições de dissuação e de redução de oportunidade ao crime àqueles indivíduos reconhecidamente dissuadíveis (marginalidade recidiva), a primeira, de forma ao estabelecimento de esquema legal de sucessíveis níveis de cerceamento, propugnando o "confinamento solitário" como remédio extremo desde que, acentua, "a única maneira inteiramente eficaz de compelir alguém a não cometer crimes é mantê-lo preso", embora reconheça que o "esquema é suscetível de objeção, como base em que qualquer limitação da liberdade de um indivíduo, fundamentado em que ele talvez cometa um crime, é incompatível com os princípios de uma sociedade livre. ("A crise urbana" págs. 270/271); a segunda, incentivando a vítima potencial do crime a cultivar e adotar providências preventivas que impeçam seu cometimento ou opondo-se-lhe rigorosas medidas que neutralizem qualquer inclinação ao delito, e, nesse sentido, poderão ser enumeradas as múltiplas providências de segurança e de vigilância, com recursos humanos especializados e implementos que a ciência coloca à disposição, além de meios outros adequados a uma ação restrita de proteção.

$\mathrm{O}$ paroxismo da segurança, hoje angustiadamente ansiada, se conseqüências outras acarreta, inevitavelmerite gera, na busca de autoproteção, um estado crescente de endurecimento nas regras de humanidade; o sentimento de enclausuramento pela natural desconfiança e suspeita e, ainda, uma corrida insofreável à recursos materiais de caráter ofensivo ou defensivo e a utilização de incentivos e equipamentos que permitem dar uma margem razoável de proteção e ipso fato, tranquilidade, independentemente das atividades são, como vimos há pouco, inadequadamente destinadas a promover a "segurança individual".

A corrida às armas defensivas, os centenares de pedidos de porte de arma e os milhares que as utilizam ao arrepio do poder controlador da Polícia Administrativa, o grau de agressividade e os requintes de violência nos ataques individuais que se vem assistindo, são suficentes para aclarar o estigma de insegurança que contagia os participantes da convivência comunitária.

$\mathrm{Da}$ exposição feita resultam algumas conclusões que podem ser dela extraídas:

1 - O direito de autoproteção está implicitamente deferido na carta magna, traduzindo tanto o resguardo da incolumidade física como a inviolabilidade dos bens patrimonais;

2 - ao poder público cabe, iniludivelmente, a segurança comunitária, a proteção ampla societária e, no exercício do poder de po'ícia, o cumprimento das normas legais de disciplinamento social; 
3 - a extensão da criminalidade e as argutas formas como é desenvolvida, aliada a impossibilidade do poder público assegurar a plena e permanente proteção individual, conduz o participante social a implementar a proteção própria através de vigilância que passe a exercitar, de modo próprio ou pela contratação de recursos humanos complementados por equipamentos de caráter preventivo;

4 - O advento, decorrente da fenomenologia delituosa, da VIGILÂNCIA PRIVADA, imposta pelo Poder Público nos casos de proteção bancária e facultativa nas demais hipóteses, configura a legalidade da instituição e referenda a necessidade de sua vigência;

5 - decorre que, com o incremento da atividade de vigilância particular sob múltiplas modalidades como exemplificadamente a vigilância residencial, vigilância comercial, vigilância industrial, vigilância bancária, vigilância de atividađes essenciais ao Estado, vigilância de logradouros públicos, em ordem de preservação do patrimônio e benfeitorias, etc., impõe-se um indispensável controle pelo Poder Público, não tantc no sentido limitativo mas com o evidente propósito de visão global da situação, desenvolvimento e perspectivas dessas atividades no quadro da vida pública;

6 - o controle, sob determinado prisma deve se exercitar amplamente no sentido de ênfase no treinamento, por departamento de formação profissional da Polícia Civil, visando uniformizar técnicas de prevenção, e adoção de uma política ou filosofia que espelhe, sobretudo, os interesses da ordem pública;

7 - finalmente, admissão de que todo o sistema de vigilância privada é inestimável auxiliar do sistema de defesa e proteção social que o Estado, com reconhecidas deficiências promove ao cidadão e a sociedade. 